\title{
Development of NRU MPEI active energy complex calculation model
}

\author{
Anna Anikeeva ${ }^{1}$, Diana Frey $^{1}$, Kirill Myakota ${ }^{1}$, Nikolay Chumachenko ${ }^{1}$, and Darya But ${ }^{1}$ \\ ${ }^{1}$ National Research University Moscow Power Engineering Institute (NRU MPEI), Russia
}

\begin{abstract}
Implementation of AEC on the basis of the Moscow Power Engineering Institute is being solved. The paper considered the technical and economic conditions for the creation of AEC in the retail electricity (power) markets. Technological, organizational and economic systems of interaction between AEC participants formed on the grounds of the MPEI CHPP. To form a business model of AEC NRU MPEI functioning, an analysis of the energy consumption balance for consumers connected to the distribution networks of the MPEI CHPP was carried out as well as analysis of the technical and economic indicators of the MPEI CHPP operation. Through the research the possibilities of the AEC of NRU MPEI for payments to the unified energy system and economic efficiency of the AEC organization were assessed.
\end{abstract}

\section{Relevance}

Many countries have taken a course towards the development of distributed energy for the present time. Distributed energy term refers to a wide range of technologies, including distributed generation, demand management, energy efficiency management, microgrids, storage, electric vehicles.

Distributed generation is a collection of power plants operating on both conventional and renewable energy sources, located near the place of energy consumption and connected directly to the consumer.

Demand Management is an adjustment of the consumers' electricity consumption to their normal load profile due to changes in electricity prices. It gives opportunity to reduce system-wide costs in exchange for incentive payments from the energy market. Nowadays a pilot project of price-dependent power reduction is implementing in Russia under the control of the system operator.

Storage means a collection of energy storage systems installed at consumers and distribution network facilities and providing, among other things, redundancy and demand management capabilities.

Electric vehicles are considered as one of the types of distributed energy resources since they play not only the role of energy consumers but also distributed storage devices.

Energy efficiency and energy saving are considered as a number of actions on the side of the electricity consumer which lead to a long-term reduction of his energy demand.

The digitalization in the electric power industry in Russia makes it possible to create a new architecture of electric power systems that meets all the requirements in terms of reliability and efficiency. One of these new elements of the energy system architecture is the active energy complex - AEC.

The digitalization in the electric power industry in Russia makes it possible to create a new architecture of electric power systems that meets all the requirements in terms of reliability and efficiency. One of these new elements of the energy system architecture is the active energy complex - AEC.

AEC is a set of facilities for production of electricity, both in the traditional way and by renewable energy sources, directly by consumers and energy storages [1]. AEC term used in this paper since it complies with the local governmental regulations [2]. In international environment it more relates to the term 'microgrid'.

AECs are intended to provide industrial enterprises with a tool for energy supply costs optimization which ensures the possibility of technologically effective and cost-efficient integration of distributed generation facilities into the Unified Energy System (UES) of Russia [2]. However, not only industrial enterprises can create such associations. Different types of microgrids already operate in other countries [3].

By the type of the energy supplied facility the following microgrids may be classified:

- Microgrids based on universities;

- Microgrids based on hospitals;

- Microgrids based on sites of the military-industrial complex;

- Microgrids based on industrial plants.

Note that foreign universities often use the organizational structure of microgrids. University 
campuses are well suited for microgrids establishing as they are located close to each other, connected by their own power grids. It is also necessary to take into account the fact that universities have research centers that need continuous power supply to save the results of research and development and experiments.

It is assumed to realize an AEC at the university in this paper. There have never been such solutions in Russia before.

By integration in the AEC, the university, the thermal power plant and other nearby consumers receive an economic effect through a decrease in the cost of consumed electricity and improvement of overall organizational efficiency. There is also system-wide savings effects take place when organizing an AEC (in the part of the power system external to the AEC). This effect requires evaluation also including an economic aspect.

The paper considered the technical and economic conditions for the participation of the AEC in the turnover of electricity in the retail electricity (power) markets. For potential AEC participants a technological, organizational and economic interaction systems were formed on the basis of the combined heat and power plant (CHPP) of NRU MPEI. The operating conditions of these systems meet the requirements of the Decree of the Government of Russia No. 507 dated June 30, 2020, namely, the installed capacity is $6 \mathrm{MW}$, which is less than $25 \mathrm{MW}$ [2]. Among potential AEC participants is also an electric grid and engineering infrastructure that provides consumption of about 33 million $\mathrm{kWh}$ per year through switchgear with $10 \mathrm{kV}$ voltage. All objects (CHPP and consumers) have electrical connections between each other through power grid facilities that do not belong to a third-party electrical grid organization. Currently, a solar power plant (SPP) with an installed capacity of $10 \mathrm{~kW}$ is in the process of commissioning. The MPEI CHPP has a regional connection with the Moscow energy system through the network facilities of PJSC Rosseti Moscow Region.

The CHPP of NRU MPEI have no consumers of electric energy (power) classified as population and categories of consumers equated to it as well as consumers of electric energy, the limitation of the consumption of which can lead to economic, environmental, social consequences.

\section{Project external environment}

The external conditions have to be considered to develop and implement a project of the active energy complex at NRU MPEI.

Russia has a two-tier system of electricity and capacity markets: wholesale and retail. Within the boundaries of the price zones of the wholesale market, the price for endconsumers of electricity is formed as a regulated price (tariff for volumes of electricity that are intended for supply to the population) and as an unregulated one. The regulated prices settle by the federal executive body in the field of state regulation of tariffs by price indexation formulas. The Federal Antimonopoly Service sets the volume of electricity and capacity supply under regulated contracts based on the consolidated forecast balance of electricity production and supply for specific producers.

The volumes of electricity not intended for population supply sell on the Day Ahead Market (DAM) and the balancing market at unregulated prices, where volumes and prices of electricity supply determined by market participants based on the ratio of supply and demand.

For the functioning of DAM, a commercial operator carries out a competitive selection of price bids from buyers and suppliers, predetermining the price and delivery volumes for each hour of the day one day before the actual supply of electricity. First, the volumes of the planned consumption include the volumes at the higher purchase price and the volumes of production with the lowest prices. Thus, supply and demand determine the market price for all participants.

When making a selection in DAM an optimization problem solves. The objective function of optimization is maximization of the welfare function of the market. The optimization problem solving taking into account the physical constraints on the production and distribution of electricity.

In the selection process for the DAM the composition of the active generating equipment is fixed including the values of the lower and upper limits of regulation as well as the optimized variables for the electricity suppliers (planned production volume) and for the consumers (planned consumption volume).

The result of the calculation on the DAM uses by the system operator to plan the operating modes of generating and receiving facilities for each hour of the operating day.

After carrying out the above actions the commercial operator for price-accepting purchase orders (price orders for purchase, indicating only amount of electricity that the consumer is ready to buy on the DAM) determines the priorities for their inclusion in the planned hourly consumption and performs the distribution of the price order among the nodes of the calculation model.

For each node of the calculation model and for each hour of the day the equilibrium prices determined from the results of the calculation will differ but all consumers and generators assigned to this node will buy electricity in this node at a given hour at a single equilibrium price determined in this node.

If there is a deviation from the planned consumption, then buying and selling carried out in the balancing market (BM). At the same time it will be possible to buy additional electricity only at a higher price and sell it at a lower price. This done to ensure that market participants do not deviate from the planned volumes of production and consumption.

However, the deviations can't be completely avoided since the DAM participants as a rule cannot withstand the load schedule obtained in the course of competitive selection due to the fact, that it is impossible to make a forecast with absolute accuracy for the factors that affect its performance. Since the balance of production and consumption must be provided in the power system at each moment of time it is necessary to compensate for the resulting deviations in real time. But these deviations can be identified only after getting information from the devices for commercial metering of electricity. 
Exactly to take into account the above-mentioned features in the electricity market that a balancing market (BM) has been organized. Within the BM, the system operator manages generation facilities in real time to balance production and consumption, taking into account the current parameters and condition of the network and generating equipment. At the end of the billing period, the commercial operator determines the volume and cost of deviations in relation to each participant in the wholesale market.

In order to make competitive selection for the BM the system operator updates the DAM calculation model for each hour of the operating day, price bids for sale submitted by the commercial operator, prompt priceaccepting requests for changes in production volumes in the BR, prompt notifications about the composition and parameters of equipment sent by participants in the wholesale market.

During competitive selection at the BM the optimization task solves. The objective function of this solution is to minimize the costs of the entire predicted demand, taking into account network constraints.

On the wholesale market, the principle of marginal node-by-node pricing implemented, taking into account losses and system restrictions on the transmission of electrical energy. The nodal calculation model allows obtain the values of equilibrium prices for each point of the electrical network. The use of the principle of marginal pricing leads to the formation of prices at the most expensive level, which is necessary to meet the current demand requested by the manufacturer. On the other hand, price signals for the development of the power system formed.

In the wholesale electricity (capacity) market, buyers are either very large consumers or buyers of electricity who purchase it for the purpose of resale to the endconsumers in the retail electricity market, for example, independent power supply companies (IPSC) and guaranteeing suppliers (GS). The principle of interaction between the subjects of the retail electricity market (REM) shown in the figure (Fig. 1).

The settlements between the consumer and the sales company can be done with any of six price categories (at the choice of the consumer and the requirements for consumer metering devices) [6]. The consumer pays the cost, including:

- the cost of electricity from the station (about $20 \%$ in the final price);

-the cost of electric power from the station (approximately $20 \%$ in the final price);

- cost of services of infrastructure organizations (JSC "ATS", JSC "Center for Financial Payments" and JSC "SO UES") (less than $1 \%$ at the final price);

- the cost of the sales markup of the energy sales company (about $5 \%$ in the final price);

- the cost of services for the transmission of electrical energy (about $54 \%$ in the final price).

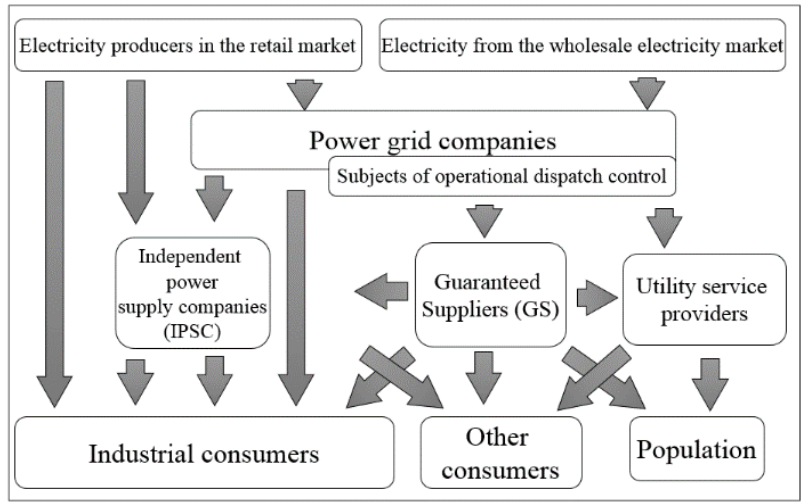

Fig. 1. Interaction of subjects of retail electricity markets.

The percentage ratio of payments that make up the final price (Fig. 2) significantly depends on the constituent entity of the Russian Federation and may differ.

Electricity consumers who have chosen the first or second price category for settlements can not reduce the cost of electrical energy (power) paid using consumption management, since calculations for the first and second price categories are carried out in relation to the total amount of electricity consumed per month for one-part the final price [6].

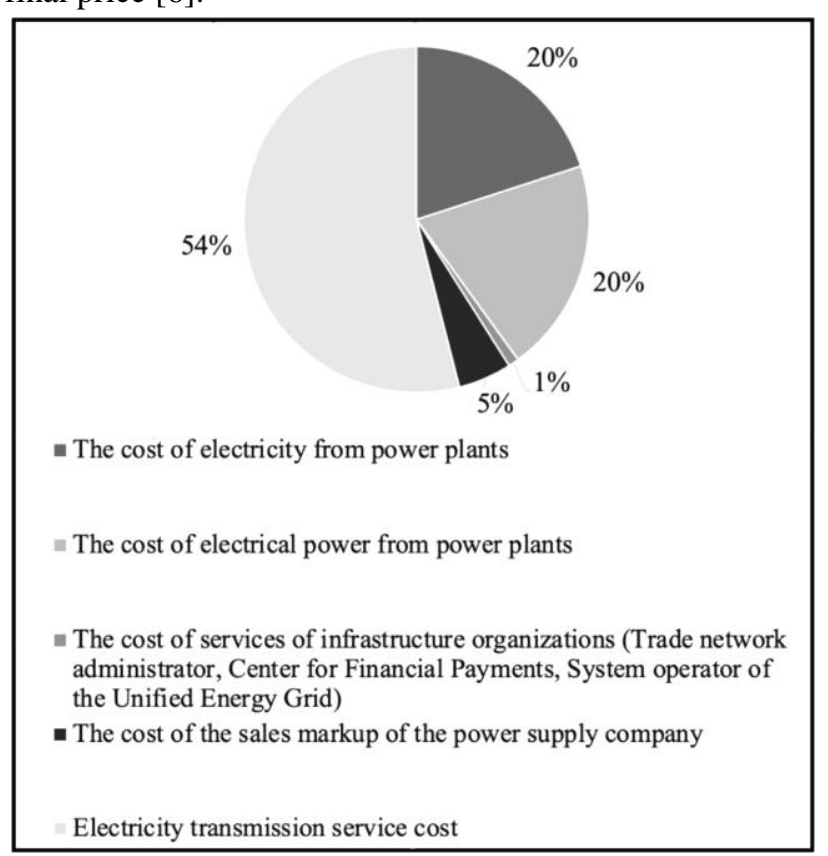

Fig. 2. Price structure.

The main components of the final cost of electrical energy (power) paid by the consumers who selected the third to the sixth price categories (PC) can be represented as follows in a simplified form:

Third price category:

- the cost of the consumed volume of electrical energy from power plants determined at hourly prices;

- the cost of the consumed volume of electric power from power plants, determined at the monthly weighted average price for capacity;

- the cost of the transmission service at a one-rate tariff.

Fourth price category: 
- the cost of electricity and capacity is similar to the components of the third price category;

- the cost of the transmission service at a two-rate tariff.

Fifth price category:

- similar to the components of the third price category, only in addition, the consumer is obliged to plan his hourly consumption and notify the sales company about it for a day (X-1) in relation to the delivery day (X), therefore the cost of deviations of the actual consumption of electricity from the planned consumption is paid separately.

Sixth price category:

- mainly similar to the components of the fourth price category but additionally the consumer is obliged to plan his hourly consumption and notify the sales company about it similarly to the fifth price category.

The volume of electric power from power plants payable by a consumer making settlements by the third to sixth price categories calculates as the arithmetic mean of the values of the volumes of electricity consumption in hours of the day, determined by JSC "ATS" in relation to the relevant guaranteeing supplier, within the boundaries of the area of operation of which the consumer's power receivers are located, for each working day of the month [7].

Consumers who have chosen the third to the sixth price category for settlements for electric energy (power), implying a separate payment for electric energy by the hour of the day and a separate payment for power, have the opportunity to reduce the cost of electric energy (power) by changing the load consumption of their power receivers by the hour days so that energy consumption is as low as possible during peak hours in the region where the consumer is located.

The retail market price depends on the cost of transmission services. Tariffs for transmission services are differentiated depending on the voltage level:

1. High first voltage (HV I);

2. High voltage (HV) - $110 \mathrm{kV}$ and above;

3. Medium first voltage (MV I) - $35 \mathrm{kV}$;

4. Secondary medium voltage (MV II) - from 1 to $20 \mathrm{kV}$;

5. Low voltage (LV) - $1 \mathrm{kV}$ and below;

6. Generator voltage $(\mathrm{GV})-110 \mathrm{kV}$ and higher in case of connection of the consumer to the power system through the switchgear of the electricity producer.

When purchasing electricity through guaranteeing suppliers the maximum level of unregulated prices (MLUP) is calculated. This is the price of electricity above which the guaranteeing supplier is not entitled to sell electricity to the consumer in the retail market.

Let's draw conclusions.

In the current model, NRU MEI must purchase electricity by unregulated prices. In case of switching to the AEC functioning model prices also remain unregulated since according to the current legislation, the population can't participate in the AEC.

NRU MPEI purchases electricity at $3^{\text {rd }}$ price category which includes the following components: differentiated by the hours of the billing period, unregulated price for electricity in the wholesale market, weighted average unregulated price for capacity in the wholesale market, one-rate tariff for electricity transmission services, sales surcharge of guaranteeing supplier, payment for other services. Both in the current situation and by integration in the AEC model, the energy consumption of NRU MPEI occurs within the framework of mechanisms and contractual structures of the retail electricity market i.e. electricity (power) purchases from a state enterprise or independent power supply company (IPSC). In the current operating model (Fig. 3), the MPEI CHPP acts as a generator on the retail electricity market.

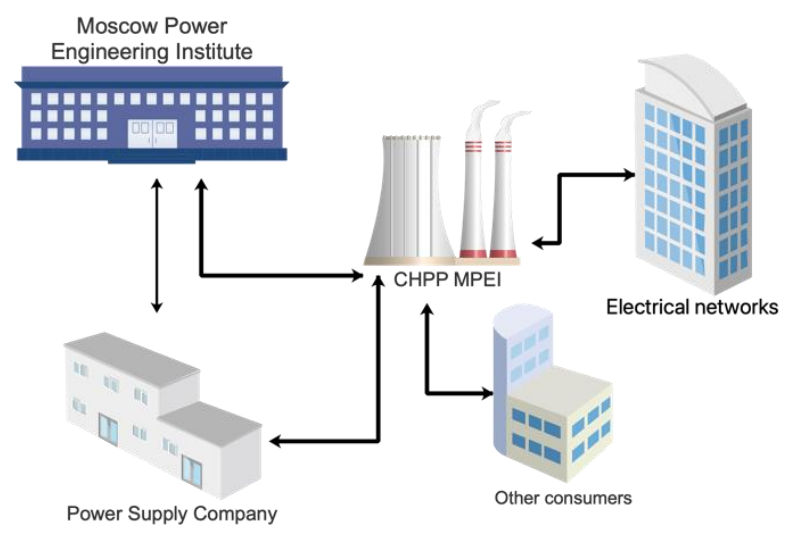

Fig 3. The current model of NRU MEI power supply.

A combined heat and power plant (CHP) is a type of thermal power plant that not only produces electricity, but is also a source of thermal energy in the form of steam and hot water in centralized heat supply systems, including hot water supply and heating of residential and industrial facilities.

Cogeneration makes it possible to use $85-90 \%$ of the energy of the fuel burned to generate electricity and heat, and reduces the total fuel consumption at CHPPs by 20$30 \%$ compared to their separate production at GRES and in boiler houses.

CHPP MPEI is a source of thermal energy for NRU MPEI and works as a laboratory of the university also.

Existing market mechanisms reduce the efficiency of combined heat and power plants, especially in the wholesale electricity market in relation to their ability to operate outside of the market mechanisms. In the conditions of market relations and free pricing the priority is not the efficient operation of equipment, which is the combined generation of electricity and heat for a CHPP but profitability of the company. The operation of CHPP plants in the retail markets allows concluding contracts with consumers that provide more predictable modes of operation of CHPP equipment that improves technical and economic indicators and reduces production cost of both heat and electric energy.

In the future, improving the technical and economic performance of the CHPP equipment may become one of the sources of additional income or savings for the AEC participants.

When switching to their own generation, consumers are exempted from paying non-market surcharges: for forced generation, subsidies to certain regions, payment for capacity under the mechanisms of power supply agreements (PSA), agreements on the provision of capacity for renewable energy sources (PSA RES), and 
the grid component that can also be used by AEC participants.

To form a business model of the AEC NRU MPEI functioning an analysis of the energy consumption balance for consumers connected to the distribution networks of the CHPP of NRU MPEI was made. The annual consumption of the NRU MPEI is 16 million $\mathrm{kWh}$ (in summer, electricity is purchased from the guaranteeing supplier of the Moscow region, which is about 3.3 million $\mathrm{kWh}$ per year). External consumers are supplied with about 15.9 million kWh per year (Fig. 4). The electricity generated by the CHPP in excess of that required for NRU MPEI is sold through an independent power supply company (IPSC).

Figure 5 shows a comparison of the energy consumption of the NRU MPEI and the Moscow region on a daily basis. Note that the hours of peak consumption coincide that means when energy is purchased from the external network, prices for the consumers will be higher than those from internal generation.

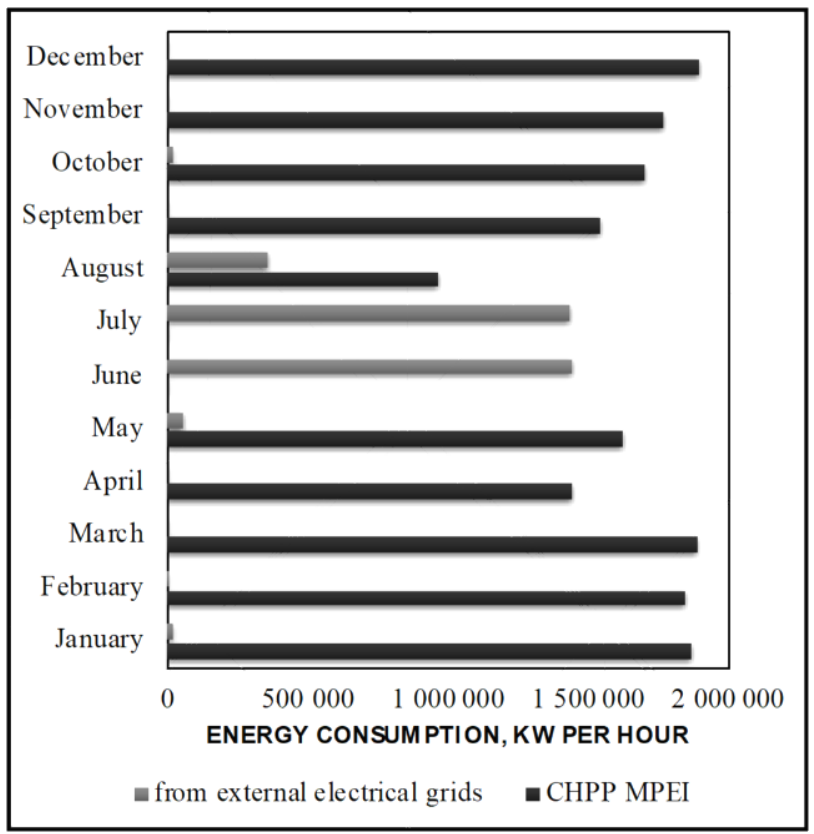

Fig. 4. MPEI Annual energy consumption.

In its turn, the generation of CHPP plants in excess of the required load level of these consumers can be sold on the retail electricity market when the AEC is organized. Therefore in the future the AEC incomes will increase.

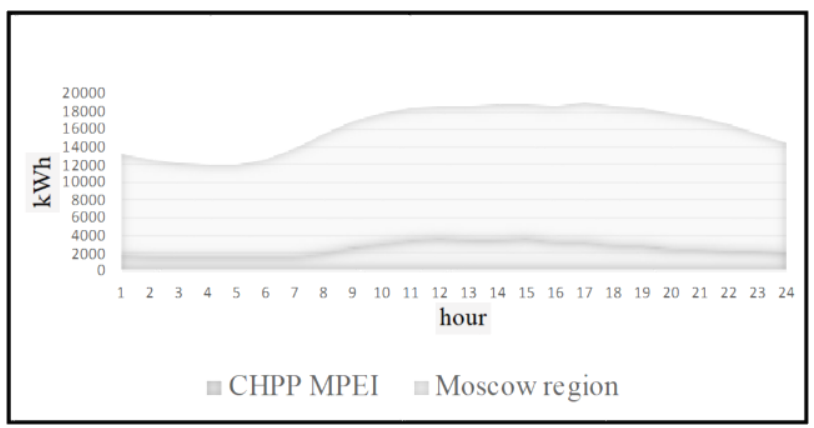

Fig. 5. Annual energy consumption of MPEI.

\section{Formation of project cash flows}

Note that when calculating the project a discount rate of $12 \%$ used as an alternative yield under capacity supply agreements (CSA).

Inflows to the AEC consisted of the following components:

- revenue of CHPP MEI, including payments from MEI, payments from other consumers, payments from NESK;

- revenue of the solar power plant (SPP);

- payments on the commission for servicing the AEC to the AEC operator.

Outflows in the AEC consisted of the following components:

- costs of CHPP MPEI;

- costs of SPP;

- costs of AEC MPEI for the maintenance of networks;

- cost of operation of software and hardware system for intelligent connection management (SHS ICM);

- cost of SPP operation;

- capital investments in SHS ICM.

In this case, to generate the project's cash flow, a method that implements the "With-without-project" principle used. First, a calculation model of the investment project of the AEC organization was made with the implementation of SHS ICM. At the second stage, the calculation model includes the cash flows of the current business model of the relationship of potential AEC participants - the "no project" state, which implies the absence of AEC implementation and the continuation of the operation of facilities within the framework of the existing mechanisms on the retail electricity market.

Since it is necessary to assess the economic efficiency for the project as a whole the cash flows of potential AEC participants have been combined to assess "without the project". Figure 6 shows that at the moment the cash flows of potential AEC participants have a negative balance the total cash flow is negative. In the current situation the cash flow represents the sum of energy supply costs of all objects connected to the distribution network and the profit of generating sources. The cost of distribution network servicing incurs NRU MPEI.

Taking into account the cost of distribution network servicing the price of electricity for NRU MPEI is high enough: 6.49 Ruble/kWh.

Further the total cash flow of the participants in the case of the creation of the AEC was modeled - the assessment "with the project". The results of calculating model "with the project" - "without the project" are shown in Figure 7.

The balance of cash flows becomes positive and covers the planned capital investments in the software and hardware system for intelligent connection management (SHS ICM). 


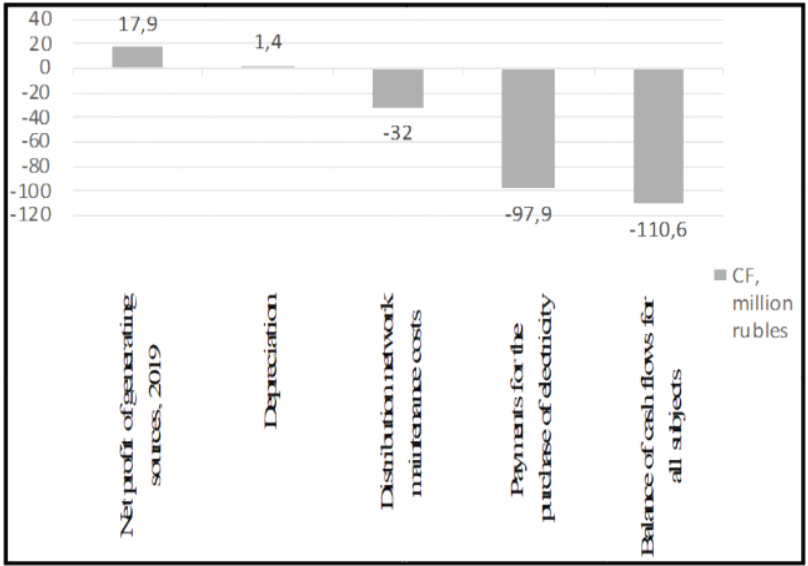

Fig. 6. Cash flows of potential AEC participants.

The remaining cash flow gives an idea of amount of payments to the power system that can be made as a part of ensuring the functioning of the AEC, as payments for reliability services, payments for grid capacity or any other mechanisms that could be created. Without taking into account payments to the power system the positive balance covers capital costs for SHS ICM in 2 months.

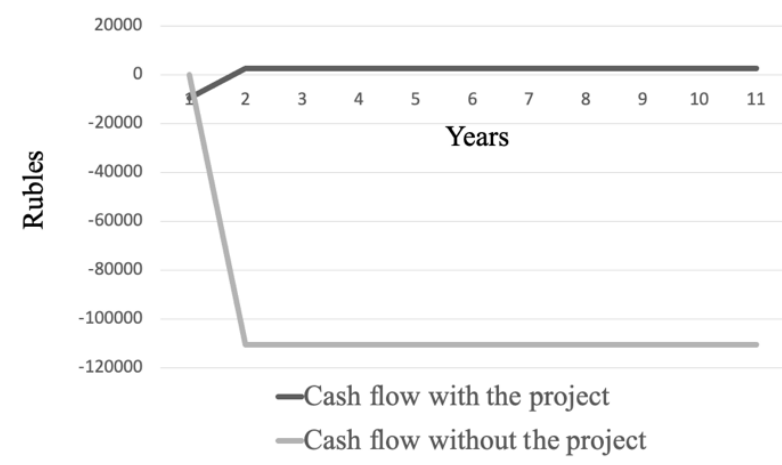

Fig. 7. Comparison of cash flows.

The assessment of AEC creation project according to the developed business model shows the NPV value for 10 years as 743284900 Rubles with investments in SHS ICM in the amount of 9530000 Rubles.

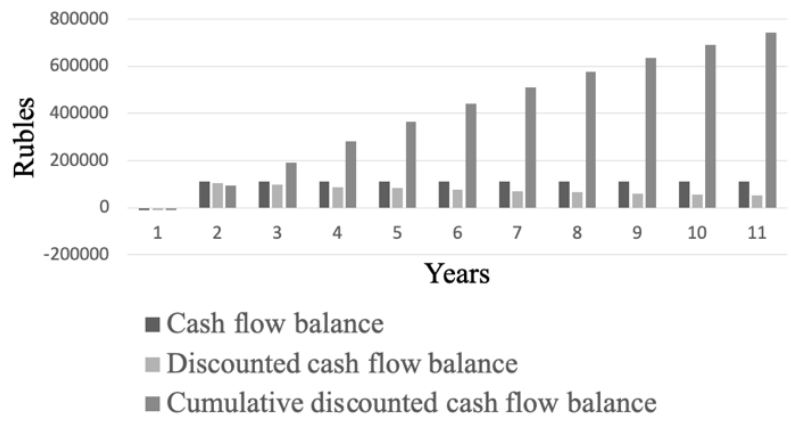

Fig. 8. Cash flow balance.

The price of electricity for consumers is decreasing and in this particular case $51 \%$ lower of the current price that confirms the efficiency of the AEC organization. It should be noted that AEC MPEI will contribute to the performance of the functions of a training and scientific center by NRU MPEI both as a technical system and as an organizational model (Figure 9).
The development of this project is possible through the creation of an energy storage system and integration into the project of experimental wind generators introduced into the educational process of NRU MPEI. Justification of the effectiveness of such solutions will require careful planning of the load distribution between generating units in order to ensure the efficiency of the entire AEC.

When implementing AEC projects it is required to evaluate system-wide effects. The considered AEC has 6 MW power that significantly differ to the power of the Moscow power system (12 $800 \mathrm{MW}$ ) so influence on the entire power system will be minimal. However, establishing of a large number of AEC, albeit of low power, in the future will require evaluation of the impact on the reliability and stability of the operation of the entire UES.

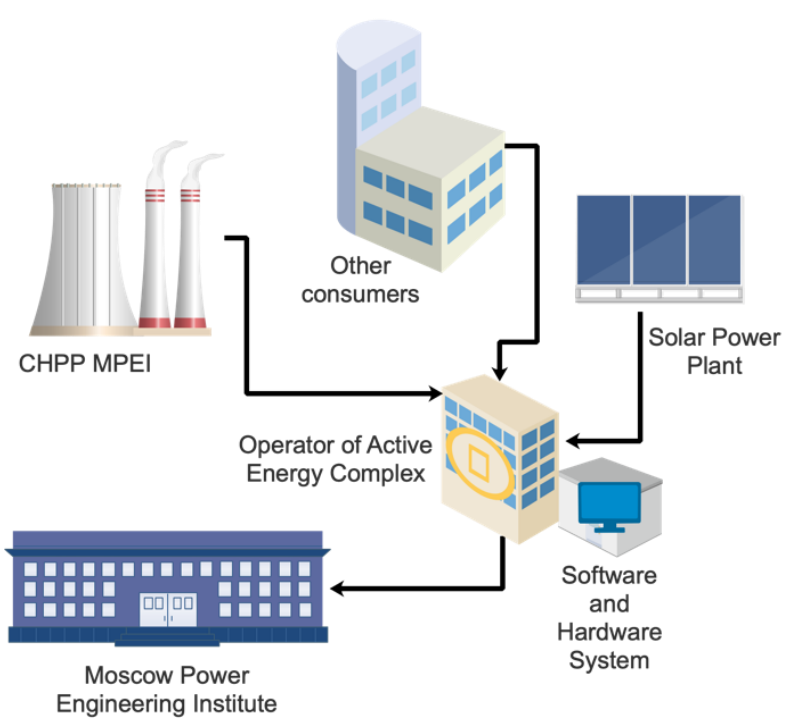

Fig. 9. Business model of Active Energy Complex (AEC) MPEI.

On the basis of the studies carried out the possibilities of the AEC NRU "MPEI" for payments to the UES were assessed. It was revealed that the greatest impact on the economic efficiency of the AEC activity is exerted by such factors as the cost of servicing of internal distribution grids, the cost of electricity production at generating units, the ratio AEC participants with energy consumption peaks in the region. These factors will make the greatest impact on the price of electricity for the AEC participants. In addition, it is important to evaluate the costs of the AEC operator responsible for settlements between the AEC participants, interaction with the external power system and for ensuring a balance between supply and demand within the AEC.

The investigation was carried out within the framework of the project "Development of the information and communication platform for interaction between the participants of the active energy complex on the retail electricity markets" with the support of a grant from NRU "MPEI" for implementation of scientific research programs "Energy", "Electronics, Radio Engineering and IT", and "Industry 4.0, Technologies for Industry and Robotics in 2020-2022. 


\section{References}

1. D. Kholkin Active energy complexes - the first step towards industrial microgrids // EnergyNet infrastructure center (2020)

2. Decree of the Government of Russian Federation No 507 dated 30.06.2020 "On the approval of requirements to controlled intelligent connection of active energy complexes"

3. D. Khilkin Digitalization as a premonition. New Business Practices in the Electricity Industry. // EnergyNet infrastructure center (2020)

4. Decree of the Government of Russian Federation No 320 dated 21/03/2020

5. Decree of the Government of Russia dated June 30, 2020 No. 507 "On approval of requirements for a controlled intelligent connection of active energy complexes"

6. Decree of the Government of the Russian Federation of May 04, 2012 No. 442

7. Decree of the Government of the Russian Federation of December 27, 2010 No. 1172 